\title{
The Effectiveness of Training Metacognition-Based Study Skill on the Students' Achievement Motivation, Self-Efficacy, Satisfaction with School and Resilience
}

\author{
Leila Karimi Jozestani, ${ }^{1,}$ Salar Faramarzi, ${ }^{2}$ and Ahmad Yarmohammadian ${ }^{2}$ \\ ${ }^{1}$ Department of Children with Special Needs, Faculty of Education and Psychology, Isfahan University, Isfahan, Iran \\ ${ }^{2}$ Faculty Member, Department of Children with Special Needs, Faculty of Education and Psychology, Isfahan University, Isfahan, Iran \\ "Corresponding author: Leila Karimi Jozestani, Department of Children with Special Needs, Faculty of Education and Psychology, Isfahan University, Isfahan, Iran, E-mail: \\ leilakarimi908@yahoo.com
}

Received 2016 January 05; Revised 2016 June 14; Accepted 2016 June 29.

\begin{abstract}
Background: Giving attention to the various factors affecting the academic achievement of student's results in their better academic performance. The aim of the current study was to examine the effectiveness of training metacognition-based study skill on the achievement motivation, self-efficacy, satisfaction with school and resilience of the female secondary students in Isfahan.

Methods: The statistical population of the present study included all the female secondary students in Isfahan in the 2014 - 2015 academic sessions among whom 30 students were selected by the multistage cluster random sampling method and were designated by the experimental research design of pretest - posttest type with control group. The interventions is related to the training study skill based on the metacognition approach drawn from Seif's educational psychology which were conducted on the test group students during 20 educational sessions. The tools used included the achievement motivation questionnaire with Cronbach's alpha reliability coefficient 0.80 , the construct validity with factor loading 0.39 , the multidimensional scale of students' life satisfaction with reliability coefficient 0.70 to 0.90 and with validity coefficient 0.50 , the self-efficacy scale with reliability coefficient 0.86 through Cronbach's alpha and the validity coefficient of correlation -0.34 , the resilience with reliability coefficient 0.86 through Cronbach's alpha and the validity coefficient of correlation 0.64. The data were analyzed through multivariable covariance analysis and the SPSS software version 22 .

Results: The results of the research revealed a significant difference between the test and control groups $(\mathrm{P}=0.001, \mathrm{~F}(4,21)=$ 6.92, Hoteling effect $=1.31$ ) thus indicating the effectiveness of metacognition training method on the achievement motivation, self-efficacy, satisfaction with school and resilience. It signifies that the metacognition training method explains $47,43,33$ and 39 percent of changes of the dependent variables respectively $(\mathrm{P}<0.005)$

Conclusions: The findings revealed that the metacognitive study skills results in the increase of the students' achievement motivation, self- efficacy, satisfaction with school and the academic resilience and it can be applied in the educational counseling of kids and teens.
\end{abstract}

Keywords: Metacognition Knowledge, Achievement Motivation, Self-efficacy, Resilience

\section{Background}

Motivation is considered as one of the significant and influential factors in human's learning and performance. Achievement motivation refers to the desire or enthusiasm for attaining success and involvement in the activities in which their success depends on the individual's effort and ability (1). Ryckman who is one of the prominent theorists on achievement motivation believes that the future of any society is dependent on the present level of its students' achievement motivation and thus the conditions of that society can be ultimately improved by promoting and improving the students' achievement motivation (2). In the course of the development of achievement motivation theory, he also suggested that in order to increase the need of individual progress, it can be taught to kids, adolescents and even to adults since according to Stipek's theory, the beliefs, values and the emotions related to progress are influenced by the environmental conditions and developmental changes. The findings of the research do not only validate the importance of achievement motivation in the growth and success of the societies, but also support the idea that achievement motivation can be improved through the presentation of suitable patterns and trainings (3). Attar Khameneh and Seif (4) demonstrated that training through the learning strategies of metacognitive study has a positive and significant effect on the students' motivation and academic achievement. It is in accordance with the research findings of Karami and Hashemi (5) which revealed that training of 
cognitive and metacognitive strategies has a positive and significant effect on the students' creativity, achievement motivation and academic self-conception.

Raynor (6) discovered that the learners with high achievement motivation show more perseverance and enthusiasm and have better performance in various tests than the learners with low achievement motivation which is in line with the finding of McClelland et al. (7). Achievement motivation, which is a significant cognitive component, is affected by several factors including environmental stimuli, personal tendencies, learning abilities and particularly self-efficacy. In progress condition, self-efficacy plays a vital role in the students' motivation and behavior (8). Bandura defines self-efficacy as the individual's belief of the ability of performing an action in a particular situation. When the individual's performance is in coordination with or beyond the individual's norms, it will result in the maintenance or increase of the self-efficacy, whereas a poor performance and beneath the individual norms will decrease the self-efficacy. Self-efficacy relates to the learners' beliefs regarding themselves, task difficulty and results of performing the task. Thus, to carry out a task successfully, individuals do not only require skill and knowledge, but also have to take a certain level of expectations for success before performing that task (9). Studies revealed that individuals with high self-efficacy exhibited better performance in various areas than those with low self-efficacy (10). There is a positive relationship between the self-efficacy and the high levels of achievement and learning as well as a wide range of academic returns such as the level of effort and perseverance in performing the difficult tasks (11). Self-efficacy also affects the kind of goals that people choose for learning (12). Bong has demonstrated that there is a positive relationship between the achievement goals and self-efficacy (13).

It should be mentioned in other discussions that difficulties in learning may result in continual failure experiences in education that will be accompanied by the parents, teachers and peers' dissatisfaction and blame (14). This dissatisfaction can negatively label these individuals as obtuse, stupid and lazy and finally will results in children and adolescents plunge into a state of embarrassment and reduce their satisfaction with life. One of the most attentive mental health factors is the amount of life satisfaction. Life satisfaction entails the individual's attitude, general assessment toward the totality of his/her life, or some aspects of life such as family life and educational experience (15). Shannon, Scott and Curoline showed that students with high level of life satisfaction do their homework better and in performing their tasks ponder more on their personal abilities, not about the chance and external factors (16). Kirkcaldy et al showed that there is a positive relationship between life satisfaction and the students' academic performance (17). The results of Stoebers research also revealed that there is a significant relationship between the age, sex, life satisfaction and different occupational, educational, physical and mental health areas (18).

Resilience is one of the other fundamental variables that in the educational environment, in spite of hardships and environmental difficulties, is considers as a very high probability of success in school and other life situations. Resilience refers to human's conformity ability in solving problems as well as to the social and interactive skills (19). Werner and Smith describe the resilience as human's inherent mechanism for self-reformation and believe that resilient people are more flexible. These people are neither invulnerable nor immune (20).

Cabrera and Padilla revealed that despite social, cultural, and economic difficulties and hindrances, resilient students experience higher levels of success in the educational environment. Through the investigation of the secondary school students (21), Martin and Marsh revealed that self-efficacy, control, planning, low anxiety, perseverance and endeavor are considered as the important predictors for resilience (22). Annalakshmi also showed that resilient people employ metacognition in explaining their behaviors and performing their tasks and also apply metacognitive thinking for decision making (23).

There are various methods for improving the students' achievement motivation, self-efficacy, satisfaction with school and resilience. One of these methods is the application of proper study method. Metacognition- based study approach is one of the novel methods of study. Metacognition refers to the cognizance of the cognition or knowing about knowing. More precisely, metacognition refers to the individual's knowledge about how he/she learns (24).

In the metacognition-based study approach, strategies are taught to the students through which they evaluate their realization, discover the amount of time needed for the study, and select a particular program for studying or solving different problems (25). Metacognition plays a vital role in learning process. Relying on the metacognition by the teacher and the learner implies that learners can promote their learning to become conscious of their thinking during the reading, writing and problem solving process, and teachers can simply promote this awareness by informing learners of effective problem solving strategies and discussing on motivational and cognitive features of thinking (26). Self-control and self-learning is the main objective of metacognitive education so that the learners become independent learners who can drive, monitor, and reform their cognitive and learning processes toward their pre-defined goals. Many of the learning and transfer of 
learning problems escalate from the lack of cognitive skills and strategies. The mentioned skills and strategies enable the individual to choose, control, monitor, manage and finally improve the cognitive processes. It is therefore necessary for learners to learn skills such as regulation, selfmonitoring, planning and goal setting in order to dominate on the cognitive strategies and create a base for the new learning. Otherwise, it would be difficult for them to solve new tasks that they have not previously deal with (27). The important role of metacognitive components and skills in effective learning has been presented unequivocally by numerous studies $(28,29)$.

Academic performance and its affecting factors have always occupied the minds of researchers of the learning area. Accordingly, application of the modern learning methods will improve the variables affecting the academic performance and thus increase the students' academic success. This process will improve the cultural, social, economic and educational fields of societies over the time. Metacognition-based skills are also one of these affecting factors.

\section{Objectives}

The aim of the present study was to investigate the effectiveness of training metacognitive-based study skills on the achievement motivation, self-efficacy, satisfaction with school and resilience of the female secondary students in Isfahan.

\section{Methods}

The current study was a pretest-posttest experimental scheme with the control (classic) group in which a test group receives the training of metacognitive study skills. Therefore, in this research the metacognitive study skills are regarded as independent variables and the achievement motivation, self-efficacy, satisfaction with school and resilience are regarded as dependent variables. The statistical population included all the female secondary students in Isfahan in the 2014 - 2015 academic session.

Multistage random cluster sampling method was employed for selection of subjects in this study. Initially, an educational region was randomly selected among 6 regions of Isfahan's education organization. Subsequently, 5 female secondary schools were randomly selected from among the schools of that region by visiting the selected region and finally, 10 classes were randomly selected from among the classes of these schools (totaling 5 schools and 10 classes). The following tools were used for data collection in this study:
1) Achievement motivation questionnaire: This questionnaire was made by Hermans in 1976 and has been standardized in Iran through different studies. It consists of 29 multiple-choice questions with incomplete sentences, with Likert response scale. The options are measured based on the achievement motivation (high to low or vice versa) and receive the scores from 4 to 1 (direct scoring for positive questions) or 1 to 4 (reversed scoring for negative questions). Scope of changes in this questionnaire is between 29 and 116. Obtaining a score above the average (58) signifies higher achievement motivation and obtaining a score lower than the average signifies lower achievement motivation. Through Cronbach's Alpha, Asgari reported the reliability of the questionnaire to be equal to 0.80 . The construct validity of the questionnaire was investigated through factor analysis and 39 percent of the questionnaire variance is predicted by the suitable factor loading (30).

2) Resilience scale: Resilience scale was introduced by Kaner and Deiwidson in (2003). This scale is a tool comprising 25 questions, which measures resilience constructs in 5-options Likert Scale from 0 to 4 . The minimum resilience score is 0 and the maximum score is 100 . The internal consistency, retest reliability and the convergent and divergent validity of the scale have been reported to be sufficient. According to Cronbach's alpha, the reliability of this test is equal to 0.86 . Validity of this construct is confirmed in Iran by Besharat (31). Moreover, Mash'al Poor (2010) has demonstrated that this construct has a high validity through its correlation with Ahwaz psychological toughness scale and calculation of correlation coefficient of 0.64 in a significant level of $\mathrm{P}<0.0001$ (32).

3) Multi-dimensional scale of satisfaction with life in the students (MELSS): This scale was introduced by Huebner et al. in 1994. This test is a self-report tool comprising 40 phrases, in which the subject should be able to determine the amount of his/her agreement or disagreement with any of these phrases in a 6 degree Likert Scale. Multidimensional scale of life satisfaction has 5 sub-scales including: family, friends, school, living environment and self. The scale's reliability coefficient (Cronbach's Alpha) in several studies was reported between 0.70 and 0.90 (33). Diow et al reported the reliability coefficient between 0.70 and 0.90. Latifian and Sheikholeslami in Iran have also reported that the reliability of this tool through retest and Cronbach's Alpha methods is between 0.70 and 0.90 respectively and this indicates that the reliability of this test is satisfactory. Discriminative validity and the convergence of this test have been confirmed through the investigation of its correlation with other tools which are related to psychological welfare (such as self-reports, teacher and parents' report). To estimate the validity of this test, its 
correlation with general health questionnaire has been reported to be equal to 0.50 (33). We employed the satisfaction with life questionnaire as the pretest and posttest in order to investigate the impressionability amount of independent variable from the dependent variable in satisfaction with life variable. It should be well known that there is no scientific questionnaire (with acceptable validity and reliability coefficients) for measuring the satisfaction with school variable. Thus for measuring this variable, we employ the Satisfaction with Life Questionnaire in which school satisfaction is one of its subscales.

4) General self-efficacy scale (GSES): This scale was introduced by Sherer et al (34) in 1982 and includes 17 items. Sherer et al, without determining its factors and items, believe that this scale measures three aspects of behavior including tendency to behavior starting, tendency to expanding the effort for completing the tasks and resistance against obstacles. Sherer et al calculated Pearson correlation between Sherer's general self-efficacy and Locus of control scale to be equal to - 0.28 . Woodruf and Kushman verified the validity of this scale through the examination of the Sherer's general self-efficacy scale. In a study by Asgharnezhad et al, for investigating the criterion validity of Sherer's general self-efficacy scale, the correlation of this scale was calculated by the Rather's Locus of control scale and this correlation was found to be equal to -0.34. In Asgharnezhad et al study for investigating the internal consistency of the scale items, the Cronbach's Alpha coefficient in Sherer et al studies was reported to be equal to 0.86 , in Woodruf and Kushman, it was equal to 0.84 , and in Asgharnezhad et al, it was equal to 0.83 (35).

According to the prior arrangements, these schools' teachers and administrators were asked to distribute achievement motivation questionnaire, multidimensional scale of satisfaction with life, self-efficacy and resilience scales in the classroom. After the collection of these questionnaires, they were scored and analyzed and those students which their scores on achievement motivation, life satisfaction, self-efficacy and resilience were lower than the cut-off score were identified of whom 30 students were randomly selected to participate in this study (36). The criteria for inclusion in this study consist of: obtaining scores lower than the cut-off score in the questionnaires; lack of any psychological, emotional and behavioral problems; consciously satisfaction; personal desire for participating in the study process and receiving no kind of behavioral or educational treatment for solving educational problems. Exclusion criteria also include the personal dissatisfaction for participating in the study process; absence from therapy sessions for more than three sessions; having any behavioral, mental and emotional problems approved by the school's psychologist or counselor and receiving treatment programs for solving their educational problems. These 30 students were then randomly assigned into test and control groups (15 students in test group and 15 students in control group). In this research, training of metacognition-based study skill was the independent variable taken from the book "Educational Psychology" by Seif (37) and achievement motivation, self-efficacy, academic satisfaction and resilience in female secondary students were the dependent variables. The in-charge author and her trained co-advisor presented educational interventions 2 sessions per week to the test group within 20 one-hour sessions according to Table 1. This research also includes one control group (receiving no intervention). It is worth mentioning that for observance of ethical issues in the study, the control group was assured that they will also be given this educational method after the completion of the study. Moreover, the sample members were explained to that their data will be kept confidential by the researchers and that their identifications will not be disclosed in the presentation of the study results. Meanwhile members of the sample group will be informed of the obtained results and the control group will receive the metacognition study skills training after the completion of the research process.

Average and standard deviation were used to analyze data in descriptive statistics while multivariable analysis of covariance (MANCOVA) was applied in deductive statistics level to determine the effectiveness of teaching metacognitive study teaching strategies.

\section{Results}

In the present study, research data were analyzed by means of SPSS 21 Software in descriptive and deductive levels. Initially, average and standard deviation (SD) were provided for the research variables (Tables 2 and 3 ) and then MACNOVA was used for the examination of assumptions (due to the control of pretest scores).

According to the above table, it is said that the average for the test group in posttest stage increased in all the four variables more than the control group. After the elimination of covariate effect (pretest) from the dependent variable (posttest), MANCOVA was applied to reflect the difference between average values. Before the test, existence of some of the most important assumptions was checked. Kolmogorov-Smirnov test results indicated that normalized data assumption is accurate $(\mathrm{P}>0.05)$. According to Table 4, precondition on the equality of all the variances has also been observed in the four variables.

According to the results presented in Table 4, the data normality assumption in all the variables $(P>0.05)$ except the satisfaction of the students in the experimental 
Table 1. Agenda of the Sessions for Metacognition Study Strategies

\begin{tabular}{lcl}
\hline Item & $\begin{array}{c}\text { Number of } \\
\text { Sessions }\end{array}$ & Description \\
\hline $\mathbf{1}$ & 1 & $\begin{array}{l}\text { An introduction to the study methods, definitions, advantages, and necessity of study methods, correct study techniques, optimal } \\
\text { conditions for efficient study, place and time, planning, timing, incorrect study techniques, and pretest }\end{array}$ \\
\hline $\mathbf{2}$ & $2-5$ & Explanation of SQ4R, and group work study for one of the lessons by this technique \\
\hline $\mathbf{3}$ & $6-8$ & Explanation of MURDER Method, and group work study for one of the lessons by this technique \\
\hline $\mathbf{5}$ & $9-12$ & Explanation of reciprocal technique, and group work study for one of the lessons by this technique \\
$\mathbf{6}$ & $13-16$ & Explanation of partnership study and learning technique, and group work study for one of the lessons by this technique \\
\hline 7 & $17-19$ & Explanation of partnership reciprocal questioning technique, and group work study for one of the lessons by this technique \\
\hline
\end{tabular}

Table 2. Average and Standard Deviation for the Test and Control Groups in Pretest Stage

\begin{tabular}{|c|c|c|c|c|c|c|c|c|}
\hline \multirow[t]{2}{*}{ Group } & \multicolumn{2}{|c|}{ Achievement Motivation } & \multicolumn{2}{|c|}{ Self-Efficiency } & \multicolumn{2}{|c|}{ Resilience } & \multicolumn{2}{|c|}{ Life Satisfaction } \\
\hline & $\mathbf{M}$ & SD & $\mathbf{M}$ & SD & $\mathbf{M}$ & SD & $\mathbf{M}$ & SD \\
\hline Experimental & 5.8 & 12.8 & 44.3 & 7.4 & 50.3 & 5.3 & 22.2 & 5 \\
\hline Control & 50.5 & 12.4 & 40.5 & 7.8 & 48.9 & 4.4 & 20.3 & 5.6 \\
\hline
\end{tabular}

Table 3. Average and Standard Deviation for the Test and Control Groups in Posttest Stage

\begin{tabular}{|c|c|c|c|c|c|c|c|c|}
\hline \multirow[t]{2}{*}{ Group } & \multicolumn{2}{|c|}{ Achievement Motivation } & \multicolumn{2}{|c|}{ Self-Efficiency } & \multicolumn{2}{|c|}{ Resilience } & \multicolumn{2}{|c|}{ Life Satisfaction } \\
\hline & M & SD & $\mathbf{M}$ & SD & $\mathbf{M}$ & SD & $\mathbf{M}$ & SD \\
\hline Experimental & 84.2 & 12.4 & 61.6 & 9.3 & 65.6 & 7.4 & 30.4 & 4.5 \\
\hline Control & 53.2 & 15.1 & 43.6 & 9.30 & 51.9 & 5.5 & 22.5 & 5.4 \\
\hline
\end{tabular}

Table 4. Kolmogorov-Smirnov Test Results to Check for Normal Data

\begin{tabular}{|c|c|c|c|c|}
\hline Variable & Group & Statics & Df & Sig \\
\hline \multirow{2}{*}{ Achievement motivation } & Experimental & 0.90 & 15 & 0.11 \\
\hline & Control & 0.97 & 15 & 0.88 \\
\hline \multirow{2}{*}{ Self-efficiency } & Experimental & 0.90 & 15 & 0.10 \\
\hline & Control & 0.94 & 15 & 0.38 \\
\hline \multirow{2}{*}{ Resilience } & Experimental & 0.85 & 15 & 0.01 \\
\hline & Control & 0.95 & 15 & 0.65 \\
\hline \multirow{2}{*}{ School satisfaction } & Experimental & 0.91 & 15 & 0.15 \\
\hline & Control & 0.96 & 15 & 0.71 \\
\hline
\end{tabular}

group were not met, because the validity of the survey, a randomly selected sample of test $F$ against the violation of some of the defaults is strengthened. Table 4 shows the condition of equality of variances observed in all four variables.

Upon checking of Table 5, equality precondition has been observed for all the co-variances and F-test will not en- counter any limitations.

Considering Levin Test, it was proposed that equality pre-condition has been observed for the variances of all the variables. This test was carried out in accordance to the important assumptions of MANCOVA and the results are presented in Table 6 .

According to Table 7, training of metacognitive study 
Table 5. Box Test for the Examination of Equality Precondition of Co-Variance Matrixes

\begin{tabular}{lcc}
\hline Sig & F & Box Test \\
\hline 0.20 & 1.33 & 15.78 \\
\hline
\end{tabular}

skills at all the four variables including achievement motivation, resilience, school satisfaction, and self-efficiency has resulted in the significant increase in the performance of test group in comparison with the control group at the posttest stage. Independent variable that descried the variance in variables of achievement motivation, resilience, school satisfaction, and self-efficiency are 78, 57, 50, and $56 \%$, respectively. Statistical power in all the above 4 variables showed the sufficiency of sample size in the analysis.

\section{Discussion}

The aim of this study was to evaluate the effectiveness of metacognition study training strategies on high school girls' achievement motivation, self-efficiency, school satisfaction, and resilience. The results of multivariable analysis of covariance (MANCOVA) revealed that interventions based on metacognition training on the achievement motivation, self-efficiency, school satisfaction, and resilience among the students of the test group had a positive and significant influence. The results of this study are in line with that of several others considering the achievement motivation being affected by metacognition training. Attar Khameneh and Seif (4) and Beckman explained that educating metacognitive study strategies has positive and significant influence on the students' educational achievement. In a research report (36), Raynor discovered that a significant relationship exists between achievement motivation and educational achievement and that those learners with high motivation manifest more assiduity and seriousness than those with low motivation. These students have better performance in the tests, which is in line with Bernard (9) and Abdollahi Abadi Ansar's (10) findings.

Students' education performance is affected by several factors, one of which is achievement motivation, i.e. tendency and interest in success. However, those students without appropriate learning strategies spend hours to study and fulfill their education affairs, which they never achieved, although, they would be able to learn in a better way by means of correct learning and study strategies. One of the tools that is with teachers for learning skills consists of empowering metacognition skills in the students since metacognition is regarded to be a key for cognitive capabilities that allows the individual to control and renovate his/her thoughts and plays a vital role in learning process.
Successful people are those who plan well, distinguish special targets, and scheme their strategies. The most significant distinction with metacognitive knowledge is that it enables the learner to be conscious of his/her learning process and achievement instant by instant and also realize his/her weak and strong points. Training metacognitive strategies may free someone from negative issues due to the short term memory weakness and inability as a result of deficiency in study strategies. Finally, that person will be well prepared in his/her lessons and optimize educational performance and increase achievement motivation.

School satisfaction is another mental health index which is been influenced by the students' achievement or failure. Life satisfaction means an individual's attitude and general evaluation on his/her life totality or some of the important aspects of life as like familial life and educational experience (15). Learning problems may lead to repetitive educational failures that may be accompanied by parents, teachers, and peers' dissatisfaction and blame. The above dissatisfaction will lead to a negative label on these persons including imbecile, stupid, and lazy and finally these children and adolescents will be filled with shame and their life satisfaction will reduce. Metacognition refers to the method of applying a person's knowledge on all the cognitive processes in order to meet learning targets. Therefore, metacognition education plan mainly focuses on human awareness of his/her cognitive system, such that he/she will eliminate all learning obstacles. Through the aforementioned method, learners will establish optimized learning techniques and adjust his/her activities throughout the whole thinking stages. This type of education will compel people to pay much attention to the realization of realities, check their selective solutions, analyze complicated problems under more detailed stages, and control their thinking process through individual questioning. Hence, acquiring such knowledge i.e. awareness of the rules, strategies, and targets will guide people to conform their cognitive capabilities to new subjects and duties in a more efficient and flexible way. Finally, upon using metacognitive strategies, the learner will be able to learn more dynamic through organizing and storing knowledge and feasibility of using them. As such, when the student acts perfectly in educational fields, he/she will get more positive attitude towards learning place (school) and finally experience more school satisfaction.

Towards effectiveness of educating metacognition study on the learners' resilience, it was concluded that persons expand their replacement system by means of metacognitive strategies. Therefore, through new ways, they will be able to evaluate and process their experiences so that resilient person can adopt different reasoning and attitude regarding all the issues. He will give much 
Table 6. Levin Test Results for the Examination of Variances Equality

\begin{tabular}{|c|c|c|c|c|}
\hline Variable & $\mathbf{F}$ & Dfi & Df2 & $\mathbf{F}$ \\
\hline Achievement motivation & 0.49 & 1 & 28 & 0.49 \\
\hline Self-efficiency & 1.08 & 1 & 28 & 1.08 \\
\hline Resilience & 0.05 & 1 & 28 & 0.05 \\
\hline School satisfaction & 0.02 & 1 & 28 & 0.02 \\
\hline
\end{tabular}

Table 7. Uni-Variate Co-Variance Analysis Results

\begin{tabular}{|c|c|c|c|c|c|c|c|c|}
\hline $\begin{array}{l}\text { Change } \\
\text { Source }\end{array}$ & Variable & $\begin{array}{c}\text { Total } \\
\text { Squares }\end{array}$ & Df & $\begin{array}{l}\text { Average } \\
\text { Squares }\end{array}$ & $\mathbf{F}$ & Sig & Effect Size & Power \\
\hline \multirow{4}{*}{ Group } & Achievement motivation & 508.092 & 1 & 508.092 & 22.002 & 0.001 & 0.47 & 0.99 \\
\hline & Resilience & 367.970 & 1 & 367.970 & 18.133 & 0.001 & 0.43 & 0.98 \\
\hline & School satisfaction & 944.134 & 1 & 944.134 & 12.270 & 0.002 & 0.33 & 0.91 \\
\hline & Self-efficiency & 420.228 & 1 & 420.228 & 15.716 & 0.001 & 0.39 & 0.96 \\
\hline
\end{tabular}

attention to himself. This thinking procedure indicates that resilient people enjoy the benefits of metacognitive strategies and use it to analyze the situation, which is in accord with the findings of Cabrera and Padilla. These researchers proposed that resilient students attain success in educational environments despite high level of problems and obstacles (21).

Several researches have been conducted concerning the influence of using metacognitive strategies that have generally indicated that those learners using correct and suitable strategies will attain greater achievement during their educational activities. Karami (5) concluded in his research that more learning and study strategies is being used by powerful students more than their weak counterpart. Many learners think of their learning problems as arising from their disabilities, whereas their actual problem is the quality of learning strategies. Metacognition plays a vital role in learning process. Relying on metacognition for a teacher and learner means that learners are able to optimize their learning to become aware of their thinking during action and the teachers can simply optimize this awareness through informing the learners about effective problem solving strategies and discussing cognitive and thinking features. Through introspection and progressive exercise, commitment, positive and personal attitude towards learning and precision, learners are able to acquire metacognitive elements (26). In this process, firstly, the responsibility of learning supervision is transferred from teachers to the learners and secondly self-perception, emotion, and positive motivation will be reinforced among the learners. As such, metacognition will build an individual's personal insights against his/her thoughts and bring up independent learning. In addition, the teacher acts as a pattern for the learners that can supervise and drive all his/her activities and teaching processes and also much of the teachers time will be spent on planning and quick realizing of patterns related to the classroom content, partnership in problem solving, supervision on learning and teaching process. When the learners do not attain the targets, the teacher will change strategies towards trying to attain cognitive and metacognitive targets in his professional life and teaching. These logical relationships in educational area may lead to the optimization of students' educational performance.

This feature must be created in the teachers if the objective is to educate the learners in order for them to take their learning responsibility. A major rationale behind the non-teaching of metacognitive skills in the classroom and not focusing on metacognitive strategies is that the aforementioned strategies are being underrated by teachers or they are ignorant of these issues. The teachers have to predispose for such learning styles by reducing teacherbase and external control. Therefore, this attitude must be transformed among the teachers. Accordingly, the teachers have to focus on learning methods and increase learning independency and learners' skills instead of the volume of learning capacities. Through teaching metacognition skills, learners are able to develop their learning skills, gain knowledge, and become very active learners.

Of the limitations in this study, applying a sample that is limited to the females and high school level as well as the limited research in Isfahan is worth mentioning. So, we have to be careful while generalizing these results to other groups, educational grades, and geographical districts. As 
such, it is recommended that this research should be carried out by means of various tools in the sample group and other educational grades in order to maximize the level of generalization, better comparison of research results, and achieving the best conclusion. Likewise, we propose to carry out the present study in other cities and provinces and compare the results with each other.

\section{Footnotes}

Authors' Contribution: Study concept and design, analysis and interpretation of data, drafting of the manuscript, critical revision of the manuscript for important intellectual content, statistical analysis: Leila Karimi Jozestani.

\section{Conflict of Interest: None declared.}

\section{References}

1. Slavin R. Educational psychology. Seyed Mohammadi, Y, trans (in Persian). Tehran: Ravan Publication; 2006.

2. Ryckman M. Theories of Personality. Belmont, printer: Thomson West; 2008.

3. Hart W, Albarracin D. The effects of chronic achievement motivation and achievement primes on the activation of achievement and fun goals. J Pers Soc Psychol. 2009;97(6):1129-41. doi: 10.1037/a0017146. [PubMed: 19968423].

4. Attar Khameneh F, Seif A. Impact of metacognitive learning strategies of student achievement and motivation (in Persian). J Educ Psychol. 2009;6(9):57-73.

5. Karami B, Karami A, Hashemi N. Effectiveness of cognitive and metacognitive strategies based on creativity, achievement and academic self-concept (in Persian). J Innovation Creativity Humanities. 2013;2(4):121-39.

6. Pashmineh A. The impact of active learning methods of adaptation and achievement motivation of students in secondary school girls in Tehran, 2006-2007 (in Persian). Tehran: Tehran Azad University, Science and Research; 2007.

7. McClelland DC, McGown DR. The effect of variable food reinforcement on the strength of a secondary reward. J Comp Physiol Psychol. 1953;46(2):80-6. [PubMed: 13044863].

8. Wolters CA. Understanding procrastination from a self-regulated learning perspective. J Educ Psychol. 2003;95(1):179-87. doi: 10.1037/0022-0663.95.1.179.

9. Benard B. Drawing forth resilience in all our youth. J Emotion Behav Problem. 1997;6(1):29-32.

10. Abdollahi Adli Ansar V. Examine the relationship between selfefficacy beliefs and locus of control and academic achievement of students of Tabriz University (in Persian). Tabriz: Faculty of Education and Psychology, University of Tabriz; 2003.

11. Linnenbrink EA, Pintruch PR. Achievement goals in the classroom, students' learning strategies and motivation processes.J Educ Psychol. 2002;80(3):260-7.

12. Elliot AJ. Approach and avoidance motivation and achievement goals. Educ Psychol. 1999;34(3):169-89. doi:10.1207/s15326985ep3403_3.

13. Bong M. Between-and within-domain relations of academic motivation among middle and high school students; self-efficacy, task-value, and achievement goals. J Educ Psychol. 2001;93(1):23-34.
14. Bakar KA, Tarmizi RA, Mahyuddin R, Elias H, Luan WS, Ayub AFM. Relationships between university students' achievement motivation, attitude and academic performance in Malaysia. Procedia Soc Behav Sci. 2010;2(2):4906-10.

15. Diener E, Suh EM, Lucas SHE. Subjective well-being: Three decades of progress. Psychological Bulletin. 1999;9(125):276-302.

16. Huebner ES, Suldo SM, Smith LC, McKnight CG. Life satisfaction in children and youth: Empirical foundations and implications for school psychologists. Psychol School. 2004;41(1):81-93.

17. Kirkcaldy B, Furnham A, Siefen G. The relationship between health ef ficacy, educational attainment, and well-being among 30 nations. $E u$ ropean Psychol. 2004;9(2):107-19. doi:10.1027/1016-9040.9.2.107.

18. Stoeber J, Stoeber FS. Domains of perfectionism: Prevalence and relationships with perfectionism, gender, age, and satisfaction with life. Pers Individ Dif. 2009;46(4):530-5. doi: 10.1016/j.paid.2008.12.006.

19. Diener E. Well-being for public policy. USA: Oxford University Press; 2009.

20. Werner EE, Smith RS. Overcoming the odds: High risk children from birth to adulthood. Cornell University Press; 1992.

21. Cabrera NL, Padilla AM. Entering and succeeding in the "culture of college": The story of two mexican heritage students. Hispanic J Behav Sci. 2004;26(2):152-70. doi: 10.1177/0739986303262604.

22. Martin AJ, Marsh HW. Academic resilience and its psychological and educational correlates: A construct validity approach. Psychol School. 2006;43(3):267-81.

23. Narayanan A. The resilient individual: A personality analysis. J Indian Academy Applied Psychol. 2008;34:110-8.

24. Karimi Jozestani L, Yarmohammadian A, Malekpor M. Effectiveness of murder's metacognitive training on dictation in third grade elementary students (in Persian). Magazine E-learning Distribution Academy. 2016;3(6):61-9.

25. Mccormid WH. Met cognitive strategies of Instruction of problem solving skills of secondary vocational students. Dissertation Abstract Inter. 2003;54(1):125-46.

26. Paris SG, Winograd P. How metacognition can promote academic learning and instruction. 1. Dimensions of thinking and cognitive instruction; 1990. pp. 15-51.

27. Hartman HJ. Metacognition in learning and instruction theory, research and practice. Dordrecht: Kluwer Academic; 2001.

28. Ghobari Bonab B, AdamZadeh F. Effects of cognitive and metacognitive strategies to improve the composition of students with learning disabilities in primary schools (in Persian). J Psychol Educ Sci Tehran University. 2007;37(1):57-71.

29. Hoseini-Nasab SD. Relationship of components of a given order with their learning achievement (in Persian). Mashhad Univ Med Sci J. 2008;32(1):369-80.

30. Homan H, Askari A. Standardized test preparation and achievement motivation. (in Persian). Psychol Res J. 2000;6(1):32-9.

31. Besharat M. Psychometric properties of the Persian form of resilience scale (in Persian). Res Report. 2007.

32. Besharat M, Abbaspour Doplani T. Relationship between metacognitive strategies and creative with the students resiliency (in Persian) New Findings J Psychol. 2011;4(1):109-22.

33. Moradi A, Taheri S. Evaluation of positive psychology students (in Persian). 1st ed. Tehran: Danjeh Poblication; 2012.

34. Sherer M, Maddux JE, Mercandante B, Prentice-Dunn S, Jacobs B, Rogers RW. The self-efficacy scale: Construction and validation. Psychol Report. 1982;51(2):663-71.

35. AsgharNejad T, Ahmadi Dahghotbedini A, Farzad V, Khodapanahi M Study the psychometric properties of general self-efficacy scale (in Persian). J Psychol. 2006;13(39):262-74.

36. Delavar A. Research methods in psychology and education (in Persian). fourth ed. Tehran: Virayesh Publication; 2008.

37. Saif A. Eductional psychology: Psychology of learning and instruction (in Persian). Tehran: Agah Publication; 2007. 